\title{
Time-Resolved Reflectivity Measurement of The Pressure-Enhanced Crystallization Rate of Amorphous Si in a Diamond Anvil Cell
}

\section{Citation}

Lu, Guo-Quan, Eric Nygren, Michael J. Aziz, David Turnbull, and C. Woody White. 1988. TimeResolved reflectivity measurement of the pressure-enhanced crystallization rate of amorphous $\mathrm{Si}$ in a diamond anvil cell. Materials Research Society Symposia Proceedings 100: 435-440.

\section{Published Version}

http://www.mrs.org/s_mrs/sec.asp?CID=1646\&DID=8855

\section{Permanent link}

http://nrs.harvard.edu/urn-3:HUL.InstRepos:2913133

\section{Terms of Use}

This article was downloaded from Harvard University's DASH repository, and is made available under the terms and conditions applicable to Other Posted Material, as set forth at http:// nrs.harvard.edu/urn-3:HUL.InstRepos:dash.current.terms-of-use\#LAA

\section{Share Your Story}

The Harvard community has made this article openly available.

Please share how this access benefits you. Submit a story.

\section{Accessibility}




\title{
TIME-RESOLVED REFLECTIVITY MEASUREMENT OF THE PRESSURE-ENHANCED CRYSTALLIZATION RATE OF AMORPHOUS Si IN A DIAMOND ANVIL CELL.
}

\author{
G.Q. LU*, E. NYGREN*, M.J. AZIZ**3), D. TURNBULL*, AND C.W. WHITE** \\ *Division of Applied Sciences, Harvard University, Cambridge MA 02138 \\ **Solid State Division, Oak Ridge National Laboratory, Oak Ridge TN 37831.
}

\section{ABSTRACT}

We have measured the pressure dependence of the solid phase epitaxial growth (SPEG) rate of self-implanted $\mathrm{Si}(100)$ by using the in-situ time-resolved reflectivity technique [1] in a hightemperature and high-pressure diamond anvil cell (DAC). With fluid argon as the pressure transmission medium, a clean and perfectly hydrostatic pressure environment is achieved around the sample. The external heating geometry employed in the DAC provides a uniform temperature across the sample. At temperatures in the range of $530-550^{\circ} \mathrm{C}$ and pressure up to $50 \mathrm{kbars}(5$ $\mathrm{GPa}$ ), the growth rate is enhanced by up to a factor of ten over that at 1 atmosphere pressure. The results are characterized by a negative activation volume of approximately $-3.0 \mathrm{~cm} 3 / \mathrm{mole}(-27 \%$ of the atomic volume). These preliminary results show a significantly weaker pressure dependence than does the previous work of Nygren et al. [2], who found an activation volume of -8.7 $\mathrm{cm}^{3} / \mathrm{mole}$. The implications of these results for the nature of the defect responsible for thermal SPEG and irradiation enhanced SPEG is discussed.

\section{INTRODUCTION}

The solid phase epitaxial growth (SPEG) of amorphous silicon produced by ion implantation has been extensively studied at ambient pressure and its kinetics are fairly well established [1]. In addition, there are two published works on the pressure dependence of SPEG in silicon. Nygren et al. [2] measured the SPEG rate of self-implanted silicon $<100>$ at pressures up to $20 \mathrm{kbars}$ ( $2 \mathrm{Gpa}$ ) in a piston-cylinder pressure apparatus with solid $\mathrm{NaCl}$ as a pressure transmission medium. They found a pressure-enhanced SPEG rate, characterized by a negative activation volume of $-70 \%$ of the atomic volume, similar to the negative activation volume found by Fratello et al. [3] for the growth of quartz from fused silica. Vasin et al. [4] implanted Si (111) with an unreported species and observed SPEG at low pressures (0-300 bars) in a gas apparatus. They reported a very slight retardation in the rate, i.e., a positive activation volume.

In both of the high pressure works above, the high-pressure annealing treatment was performed separately from the determination of growth velocity. In the former [2], the growth velocity was measured using Rutherford backscattering and channeling techniques, while in the latter [4], the growth velocity was obtained from sheet resistivity measurements. Recently, Licoppe et al. [5] used the in situ time resolved reflectivity (TRR) technique, developed by Olson et al. [6], to observe a pressure-enhanced SPEG rate of GaAs in a gas apparatus at pressures of up to 5 kbars. The in situ technique has several advantages over the post-mortem measurements performed previously. Instantaneous measurements of the growth rate eliminate the need for assumptions about its time-dependence; they also eliminate sample-to-sample variations by allowing growth rates under varying conditions to be measured on the same sample.

In this work, we have perfomed TRR measurements of the SPEG rate in self-implanted Si $<100>$ in a high-temperature and high-pressure diamond anvil cell (DAC), which can attain pressures of hundreds of kilobars. Fluid argon, loaded cryogenically, is used as the pressure transmission medium to ensure a clean and perfectly hydrostatic environment around the sample.

\section{EXPERIMENT}

A wafer of $S i(100)$ (p-type, $1+2 \Omega-\mathrm{cm}$ ) was polished on both sides to a thickness of $25-40 \mu \mathrm{m}$ and implanted on both sides at $77 \mathrm{~K}$ with ${ }^{30} \mathrm{Si}^{+}$(each side at $180 \mathrm{keV}, 2 \times 10^{15} / \mathrm{cm}^{2}, 0.4 \mu \mathrm{A} / \mathrm{cm}^{2}$; and at $60 \mathrm{keV}, 1 \times 10^{15} / \mathrm{cm}^{2}, 0.4 \mu \mathrm{A} / \mathrm{cm}^{2}$ ). The implantation procedure produced an amorphous 
layer approximately $3000 \AA$ thick. The wafer was then cut into many $200 \mu \mathrm{m} \times 200 \mu \mathrm{m}$ square samples.

The diamond anvil cell used in this study is designed after the Piermarini-BIock cell [7] with added external heating geometry. In Fig. 1 we show a schematic of the pressure chamber. The pressure is applied with a $0.7 \mathrm{~mm}$ diameter surface of each diamond anvil. Metal gaskets were made out of $10 \mathrm{mil}(254 \mu \mathrm{m})$ thick Inconel $\times 750$ sheet. The gaskets were preindented with the diamonds; holes of about $350 \mu \mathrm{m}$ in diameter were subsequently drilled in the center of the indentation. After placing the silicon sample and several small $(5-10 \mu \mathrm{m})$ ruby chips into the gasket hole, the cell was cooled to liquid nitrogen temperature while gaseous argon flowed across the diamonds. The chamber was sealed after a sufficient quantity of liquid argon condensed to fill it.
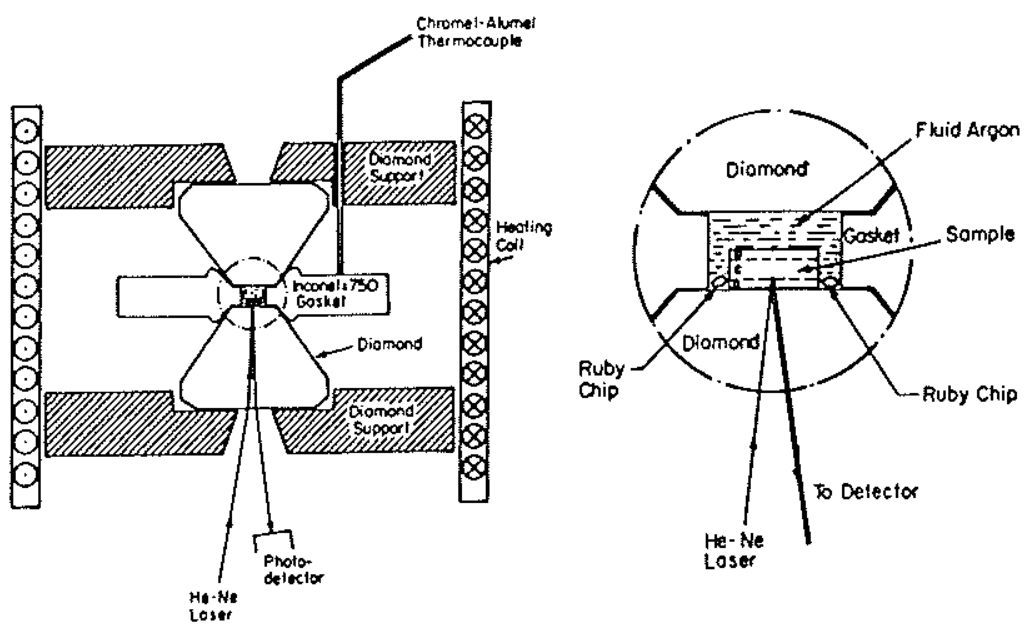

Fig. 1. Schematic of the pressure chamber of the high-temperature and high-pressure diamond anvil cell.

The ruby fluorescence technique [8], which measures the pressure-induced shifts of the ruby fluorescence lines $(692.7 \mathrm{~nm}$ and $694.2 \mathrm{~nm}$ ) excited by an argon ion laser, was used to measure the pressure on the sample.

The cell was heated by using resistive heating coils. A chromel-alumel thermocouple, placed next to the diamond and in contact with the gasket, was used to monitor the temperature. During the course of an annealing run, temperature stability of $\pm 0.5^{\circ} \mathrm{C}$ was maintained. TRR signals from a HeNe laser $(\lambda=693 \mathrm{~nm})$ focussed on the sample were detected with a photodetector and recorded onto a chart recorder.

\section{RESULTS AND DISCUSSION}

In Table I we list the runs and the resulting growth velocities. The ambient pressure runs were done in the DAC in air (no argon loading); the growth velocities obtained with this method are in good agreement with published values for similar materials.[2] In Fig. 2(a) we show the TRR signal at ambient pressure and $550^{\circ} \mathrm{C}$. The distance between two reflectivity maxima corresponds to the interface traversing a distance of $652 \AA$; hence, this crystal grew at a rate of $0.35 \AA / \mathrm{sec}$. In Fig. 2(b) we show the TRR signal at $530^{\circ} \mathrm{C}$ and $50 \pm 5 \mathrm{kbars}$. Despite the lower temperature compared to Fig. 2(a), this crystal grew at almost twice the rate. 
Table I: conditions and results of high pressure runs

$\begin{array}{cccc}\text { Table 1: conditions and results of high pressure runs } \\ \text { Run \# } & \text { Temperature }\left({ }^{\circ} \mathrm{C}\right) & \text { Pressure (kbars) } & \text { Velocity }(\AA / \mathrm{sec}) \\ 1 & 566 & \text { Ambient } & 1.0 \\ 2 & 550 & \text { Ambient } & 0.35 \\ 3 & 550 & 27 \pm 5 & 1.284 \\ 4 & 550 & \text { Ambient } & 0.37 \\ 5 & 540 & \text { Ambient } & 0.140 \\ 6 & 530 & 50 \pm 5 & 0.667\end{array}$

Assuming crystal growth to be a simple thermally-activated process, the growth rate is expressed phenomenologically by:

$$
\mathrm{v}=\mathrm{v}_{\mathrm{o}}(\mathrm{T}) \exp \left(-\mathrm{P} \Delta \mathrm{V}^{*} / \mathrm{RT}\right) \text {, }
$$

where $\Delta V^{*}$, the activation volume of the SPEG process, can be found from the slope of the $\ln v \mathrm{vs}$ $P$ plot. Within the context of transition state theory, $\Delta \mathrm{V}^{*}$ is the volume of the transition state minus the volume of the initial state. In Fig. 3 we plot the pressure dependence of the SPEG rates at $550^{\circ} \mathrm{C}$ and $530^{\circ} \mathrm{C}$ from the data in Table I. The ambient pressure velocity at $530^{\circ} \mathrm{C}$ was extrapolated from the three measured ambient pressure velocities, and is in reasonable agreement with published values. The activation volume, $\Delta V^{*}$ is found to be approximately $-3.0 \pm 0.5$ $\mathrm{cm}^{3} / \mathrm{mol}$, which is about $27 \%$ of the atomic volume of crystalline silicon $\left(12 \mathrm{~cm}^{3} / \mathrm{mol}\right)$.
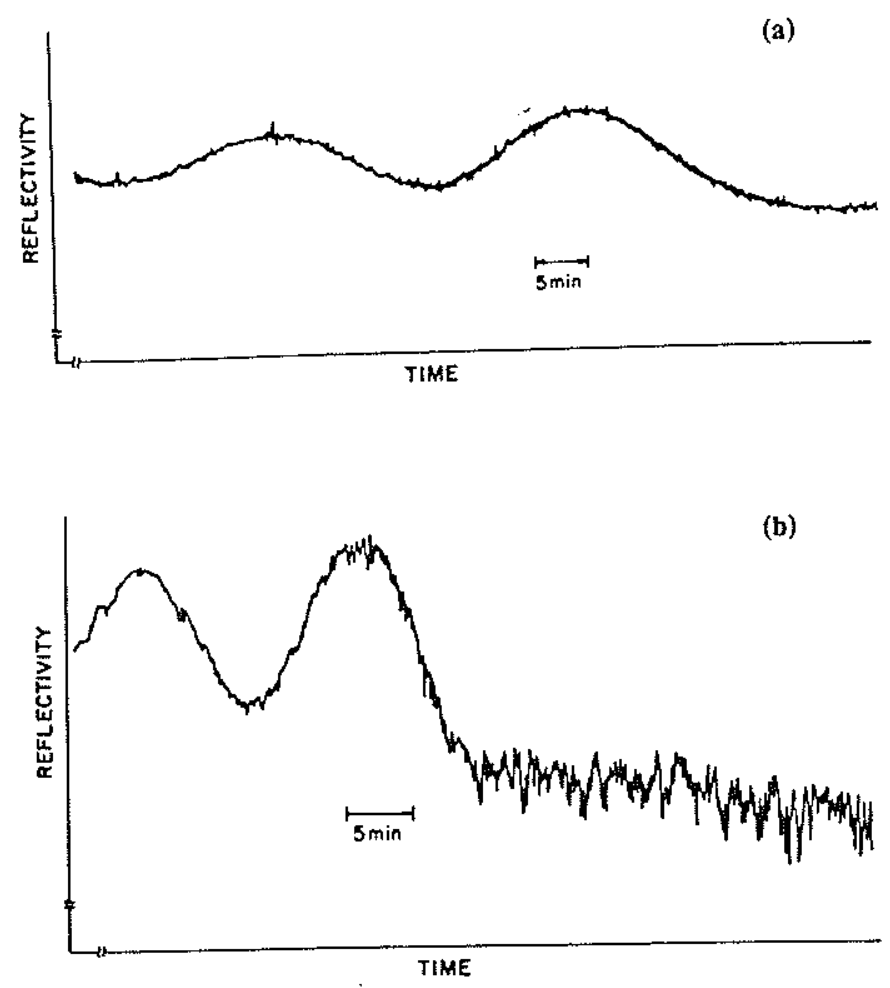

Fig. 2. (a) TRR signal at ambient pressure and $550^{\circ} \mathrm{C}$. The SPEG velocity was $0.35 \AA$ A sec. (b) TRR signal at $50 \mathrm{kbars}$ and $530^{\circ} \mathrm{C}$. The SPEG velocity was $0.667 \mathrm{~A} / \mathrm{sec}$. 
The activation volume is negative, which means phenomenologically that the population of a lower-volume transition state is increased, relative to that of the starting state, by the application of pressure. This finding is in qualitative but not quantitative agreement with that of Nygren et al., who found an activation volume of approximately $70 \%$ of the molar volume for the sane process. Ours is a significantly weaker pressure dependence. It is possible that nonhydrostatic stresses in the previous experiment affected the results.

The ruby fluorescence technique for pressure measurement is very simple and can be very accurate. However, the accuracy was not optimized during these preliminary experiments, and we estimate an uncertainty of $\pm 5 \mathrm{kbars}$ in the pressure measurements. Because at high temperatures $\left(>300^{\circ} \mathrm{C}\right)$, the ruby lines broaden to such an extent that the determination of the fluorescence peak positions becomes impossible, the pressure on the sample was measured at room temperature. The pressure was measured twice, once before the annealing run and once after. Through proper calibration techniques, we should be able to determine the pressure at elevated temperature and its relation to that measured at ambient temperature. At this point, we believe that the difference is small, and that the pressure at high temperature could be slightly lower than the one measured at room temperature. This judgement is based on the fact that the Belleville spring washers, which are used to produce the force on the diamonds, were slightly heated (to about $80^{\circ} \mathrm{C}$ ) during the anneal, which could lead to a slight decrease in the spring constant of the washers and a lower pressure. In addition, the difference in thermal expansion between the argon pressure medium and the gasket material may lead to a change in pressure with temperature, even if the load on the diamond anvils is kept constant.

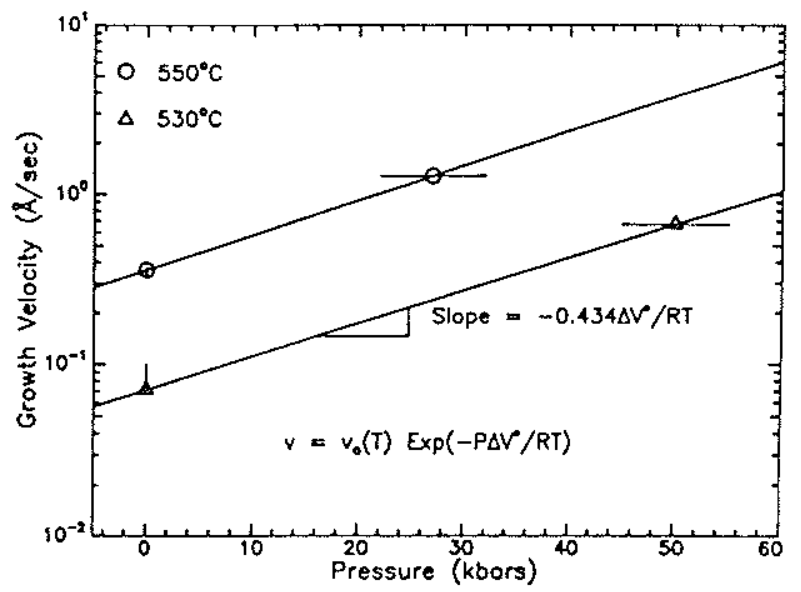

Fig. 3. Growth rate vs pressure at $530^{\circ} \mathrm{C}$ and $550^{\circ} \mathrm{C}$. The activation volume is approximately $-3.0 \pm 0.5 \mathrm{~cm}^{3} /$ mole.

The $652 \AA$ peak-to-peak distance of the TRR signal used to calculate the SPEG velocities is equal to $\lambda / 2 \mathrm{n}$, where $\mathrm{n}$ is the index of refraction of amorphous Si at this wavelength. Since $n$ in general depends on the pressure, the SPEG velocities calculated from the TRR signals should take this effect into account. We have observed the total times needed to completely crystallize the amorphous $\mathrm{Si}$ layer at $550^{\circ} \mathrm{C}$ at ambient and at $27 \mathrm{kbars}$. We have found that the time ratio matches the inverse of the indicated velocity ratio. Hence the effect of pressure on the index of refraction is negligible. 
There is a considerable amount of recent work relevant to the nature of the atomic defects responsible for SPEG [9-15]. Recent experiments in.irradiation enhanced SPEG have established a temperature dependence of approximately $0.3 \mathrm{eV}$ for this process [14;15]. This number has been associated with the activation energy for migration of a SPEG defect. Assuming that there is a single type of defect controlling both thermal SPEG and irradiation enhanced SPEG, whose migration to the boundary is the rate-limiting step in ion-induced SPEG, an exponentially pressureenhanced growth rate can be used to place an upper limit on $\Delta V_{f}$, the formation volume of such a defect. A lower limit of $-50 \%$ of $\Omega_{\mathrm{a}}$, the atomic volume, is obtained for $\Delta \mathrm{V}_{\mathrm{m}}$, the migration volume, by realizing that the PV term in the free energy barrier to migration cannot reduce it to zero without being reflected in a break in the pressure-dependence data. In our work, the overall activation volume, which is the sum of $\Delta \mathrm{V}_{\mathrm{f}}$ and $\Delta \mathrm{V}_{\mathrm{m}}$, is $-27 \%$ of $\Omega_{\mathrm{a}}$. Hence $\Delta \mathrm{V}_{\mathrm{f}}$ cannot be greater than $+0.23 \Omega_{\mathrm{a}}$. It is very unlikely that this defect could be a vacancy because this number, percentage-wise, is much smaller than the $70 \%$ of the atomic volume estimated by Scholz and Seeger [16] for the vacancy volume in germanium, for which they took into account the lattice relaxation around the vacant site. Since Si is more tightly bound than $\mathrm{Ge}$, one might expect that in $\mathrm{Si}$ the relaxation around the vacant site could be less, leading to a larger percentage of $\Omega_{\mathrm{a}}$ for the vacancy volume. If subsequent experiments establish an exponentially increasing pressuredependence to yet greater pressures, the maximum possible value of $\Delta V_{f}$ will be pushed further down.

\section{CONCLUSIONS}

We have measured the pressure dependence of the solid phase epitaxial growth rate of selfimplanted $\mathrm{Si}(100)$ by using the in-situ time-resolved reflectivity technique in a high-temperature and high-pressure diamond anvil cell (DAC). At temperatures in the range of $530-550^{\circ} \mathrm{C}$ and pressure up to $50 \mathrm{kbars}(5 \mathrm{GPa})$, the growth rate is enhanced by hydrostatic pressure and is characterized by a negative activation volume of approximately $-3.0 \mathrm{~cm}^{3} / \mathrm{mole}(-27 \%$ of the atomic volume). We find a somewhat weaker pressure dependence than was found by Nygren et al. in earlier work. If these preliminary data are substantiated by more thorough studies now in progress, we can draw the following conclusion conceming the nature of the defect controlling SPEG: if there is a single type of SPEG defect in both thermal SPEG and irradiation enhanced SPEG, whose migration to the boundary is the rate-limiting step in ion-induced SPEG, then its volume is no greater than $23 \%$ of the molar volume of crystalline $\mathrm{Si}$.

\section{ACKNOWLEDGMENTS}

The authors gratefully acknowledge Dr. G. J. Piermarini from NBS-Gaithersburg for providing us his DAC blueprints and many helpful discussions concerning the design of and use of the diamond anvil cell. We also thank Dr. K. Goettel, Prof. I. F. Silvera, and J. Bumett for their help with pressure measurements and P. H. Fleming for her skilled assistance with sample preparation. Work at Harvard was supported by the Harvard Materials Research Laboratory under NSF-DMR86-14003 and by the Office of Naval Research under contract N00014-85-K-0023. Work at ORNL was supported by the U.S. Dept. of Energy under DE-ACO5-84OR21400. One of us (M.J.A.) was supported in part by an appointment to the U.S. Dept. of Energy Faculty Research Participation Program administered by Oak Ridge Associated Universities.

\section{REFERENCES}

a) Permanent address: Division of Applied Sciences, Harvard University, Cambridge MA 02138.

[1] G. L. Olson, S. A. Kokorowski, J. A. Roth, and L. D. Hess, in Mat. Res. Soc. Symp. Proc. 13,141 (1983).

[2] E. Nygren, M. J. Aziz, D. Turnbull, J. M. Poate, D. C. Jacobson, and R. Hull, Appl. Phys. Lett., 47, 232 (1985).

[3] V. J. Fratello, J. F. Hays, and D. Turnbull, J. Appl. Phys. 51, 4718 (1980). 
[4] A. S. Vasin, V. I. Okulich, V. A. Panteleev, and D. I. Tetel'baum, Sov. Phys. Solid State 27. 168 (1985).

[5] C. Licoppe and H. Savary, Appl. Phys. Lett. 51, 740 (1987).

[6] G. L. Olson, S. A. Kokorowski, R. A. McFarlane, and L. D. Hess, Appl. Phys. Lett. 37. $1019(1980)$.

[7] G. J. Piermarini and S. Block, Rev. Sci. Instrum. 46, 973 (1975).

[8] R. A. Forman, G. J. Piermarini, J. D. Bamett, and S. Block, Science 176, 284 (1972).

[9] G. Lulli, P.G. Merli, and M. Vittori Antisari, these proceedings (Mat. Res. Soc. Symp. Proc. $100(1988)$.)

[10] A. La Ferla, E. Rimini, S. Cannavo, and G. Ferla, these proceedings (Mat. Res. Soc. Symp. Proc. 100 (1988).)

[11] S. T. Pantelides, these proceedings (Mat. Res. Soc. Symp. Proc. 100 (1988).)

[12] L. E. Mosley and M. A. Paesler, these proceedings (Mat. Res. Soc. Symp. Proc. 100 (1988).)

[13] F. Spaepen and D. Tumbull, AIP Conf. Proc. 50, 73 (1979).

[14] J. Linnros, B. Svensson and G. Holmden, Phys. Rev. B30, 3629 (1984).

[15] J.S. Williams, R.G. Elliman, W.L. Brown and T.E. Seidel, Phys. Rev. Lett. 55, 1482 (1985).

[16] A. Scholz and A. Seeger, Phys. Stat. Sol. 3, 1480 (1963). 